\title{
CONFERENCIAS PATRIOTICAS
}

\section{Carta da maior Gloria da RAÇA LAtina.}

Petropolis, 31 Março, 1918.

Ruy Barbosa, agradece, ao seu illustre collega Dr. Braz de Sousa Arruda, o obsequio da offerta do exemplar, que lhe remetteu, das suas notaveis Conferencias Patrioticas e as palavras de extrema bondade, com que lh'as enviou.

$* * *$

CARTA DO "PRINCIPE DOS POETAS BRASIlEIROS", o saudoso Olavo Bilac.

Rio, 16 de Abril de 1918.

Amigo Snr. Dr. Braz de Sousa Arruda.

Muito obrigado pela remessa dos exemplares do volume das suas admiraveis Conferencias Patrioticas.

O seu talento e o seu enthusiasmo, são e serão abençoados pela contribuição do seu valor moral á victoria dos nossos ideaes civicos.

Affectuosos abraços do seu am. ${ }^{\circ}$ e admdor. Olavo Bilac.

\section{OBSERVAÇÃO PRELIMINAR}

Sem ligações partidarias, sem nenhuma suggestão, por impulso unicamente de patriotismo emprehendi essa cruzada em prol da civilização e em defesa dos direitos da terra que me viu nascer. Nunca me foi mais leve um trabalho tão pesado qual o que tomei sobre meus hombros, animado apenas por alguns patriotas, a quem agradeço, pedindo ao mesmo tempo que acceitem a publicação 
que ora faço como sendo um preito á generosidade com que acudiram ao meu appello. Não posso deixar de agradecer aos exmos. srs. Coronel Leopoldo Amaral, Dr. Laudo de Camargo e Coronel Luiz Arruda Barbosa, pelo modo attencioso com. que me receberam, e deram todas as providencias, ao intento de tornar possivel a realização da empreza em que me empenhei.

Felicito-me pela fórma por que, em toda parte, foram recebidas minhas palavras, prova de quanto é vivo no peito brasileiro o fogo do patriotismo. Moço e crente, vejo felizmente augmentar minha confiança no futuro de minha patria, quando sinto, de todos os lados, sympathias pela cruzada que tomei ao meu cargo, quando ouço applausos ás minhas palavras, procurando avivar o sentimento sagrado de amor á patria em meus concidadãos.

Possam essas modestas conferencias ter tido alguma influencia no sentimento de patriotismo dos brasileiros, tão facil de ser animado.

\section{SANTA CRUZADA}

Conferencia pronunciada em Campinas.

Quando, na Edade Média, o servo dava toda a sua attenção aos rudes trabalhos agricolas, lembrado unicamente da severidade do villico, o castellão dividia o tempo entre os ocios do lar e as diversóes de caça e dos torneios, a dama orava, cuidava de doces prácticas, e escutava os trovadores, ouvia-se subito a voz de Pedro, o Eremita, de S. Bernardo, de Foulques de Neuilly, que convocava os christãos a irem á conquista do Santo Sepulcro. Era a cruzada, a lucta sancta contra os infieis que se abria, era o adeus ao doce tempo da paz, era a partida para terras 
longinquas, donde muitos nunca mais tornariam. Choravam as damas e as mulheres do povo, e havia carregume em todos os semblantes. Entretanto cumpria partir, entretanto os pregadores falavam em nome da religião, e annunciavam uma dura necessidade, qual a de conter o progresso rapido do crescente turco, a ameaçar continuamente a -civilização occidental. Enganam-se os que suppõem que as cruzadas tinham por unico escopo a conquista dos sanctos logares. De nenhum modo. Desde que, desembarcando em Tarifa, e tendo batido os Wisigo dos em Xeres, ameaçou Tarik, á frente de seus arabes, a Europa inteira, todos os homens de alta cultura prognosticaram a possivel queda da sociedade occidental, e o perigo da civilização formada á sombra dos principios do Evangelho. Até que D. João d'Austria, commandando as forças reunidas de Veneza, de Hespanha e do Papa, houvesse anniquilado, em Lepanto, a 7 de Outubro de 1571, a esquadra ottomana, foi o turco ameaça perenne ao occidente, ao christianismo, á paz européa. Dessa epopéa de quasi dez seculos entre chistãos e mahometanos, nada mais são do que rapidos, mas bellos e heroicos episodios, a lucta dos portuguêses em Africa, è a dos hespanhóes, dentro mesmo de sua patria, contra os arabes... Ora, é precisamente esse momento terrivel na vida da humanidade culta que hoje se reproduz. E' a alliança, com a mais nefanda falsia, entre um povo que se diz christão e o turco que põe hoje em perigo tudo quanto nossos avós fizeram em prol da humanidade, inspirados pela doutrina sacratissima pregada por Christo.

Não foram as cruzadas actos de tão pura abnegação, não o é a lucta actual contra os imperios centraes, barbaros que tragicamente surgem, sedentos de sangue, cheios de odio, contra os povos laboriosos, emprehendendo, parece, a guerra pelo prazer criminoso de queimar, destruir, incendiar, assassinar mulheres e crianças, quiçá beber no cra- 
neo dos inimigos, como faziam, em seus festins, os avós do Kaiser, celebrados e cantados na poesia popular legada aos posteros. Temos necessidade de nos defender. Não movemos a guerra, acceitamol-a, como disse o Conselheiro Ruy Barbosa, e repetem-no aquelles a quem confiámos os destinos da patria brasileira. Foram os allemães que torpedearam nossos navios, foram elles que sacrificaram vidas de brasileiros innocentes, foram elles que nos impediram de commerciar livremente, foram elles que violaram os direitos dos neutros, tão custosamente estabelecidos pelos constituidores do Direito das Gentes, foram elles que se emboscaram á nossa passagem, e, quaes assassinos, descarregaram suas armas sobre transeuntes inermes, lançaram ás profundezas do oceano as riquezas que, sob o sol ardente dos tropicos, curvados sobre a terra estuante, haviamos produzido, cortaram a vida preciosa de nossos irmãos, de filhos queridos, de pobres creanças amamentadas pelas brasileiras, innocentes que desceram aos insondaveis abysmos do oceano banhados, ungidos pelas lagrimas das extremosas mães, victimas da crueldade desses novos hunos. Sim! Hunos. Os soldados de Attila não eram mais crueis, o flagello de Deus não cahiu com mais rigor sobre a Terra, que as balas e torpedos dos allemães sobre nossos navios. $\mathrm{O}$ genero humano, em um grito unisono, protestou contra a guerra submarina. Todos os povos da America, toda a Europa culta, em paginas que o tempo não apagará, mais duradouras que a crueldade alleman, licção eterna para nossos netos, documento eloquente de nossa actual cultura, calumniada pela ferocidade dos imperios centraes, protestaram contra a selvageria do povo que se julga predestinado. Mas do barbaro que se mostrava insensivel a todos os encantos europeus, a tudo quanto produziu a civilização, disse Camões o mesmo que hoje poderemos dizer do idolo da Allemanha. A nada disto o bruto se moveu.... 
Mas, reatando o fio de nossas idéas: si outrora corria ao frade, encerrado no mosteiro, para onde fugira toda a sciencia, escapa da invasão dos barbaros, daquelles que são sociologicamente falando representados hoje pelos allemães, corria ao frade o dever de despertar o povo descuidoso, que mal sabia haver no oriente ferozes turcos, hoje é a nós, homens da sciencia, e aos que têm em suas mãos os destinos da nossa patria, que cabe o cuidado de dar ao povo noticia dos perigos que o assoberbam. Quando no vasto, intermino oceano, navegava-se tranquillamente, subito o marinheiro vigilante dá o signal do perigo. Tudo se modifica. Tomam-se as precisas cautelas, e vidas preciosas são postas a salvo graças ao cuidado, á solicitude daquelle a quem foi confiado o difficil posto de velar pela segurança commum. E' o que ora fazemos, nós homens intellectuaes. Si muito se falou em perigo amarello, nunca verdadeiramente nelle se pensou na culta Europa, nem na joven America. Do perigo germanico, da mania perigosissima do pan-germanismo, quasi nada se disse, nunca se pensou em tal. Só Renan e Eça de Queiroz, e pouquissimos outros espiritos lucidos, previdentes, deram avisos premonitorios, infelizmente passados despercebidos, sob o ruido da civilização, entretidos os homens pelo trabalho quotidiano. Disse bem Ihering que só acreditamos na guerra, quando troa o primeiro tiro de canhão: até então, descuidosos dormimos, pensando que a paz é eterna, que a guerra é uma instituição dos tempos barbaros, fossil de que só temos noticia pelos livros, pelos poemas heroicos, pelo dramas e pelas tragedias no theatro... Não é ésta crença só cultivada pelo povo, facil em acreditar naquillo que deseja que seja uma realidade, mas tambem é a opinião de espiritos cultos. Foi Comte, tão douto na Historia, quem proclamou que haviamos superado o estadio da guerra de conquista, e mesmo da de defesa, julgando que entráramos francamente 
no periodo industrial, ou de lucta com a natureza, ao intento de melhorar nossas condições materiaes, ou economicas. Foi elle com tudo que, como diremos em outra conferencia, mostrou, espirito lucido, que o allemão não tem a mesma psychologia que os povos latinos, não assimila nossa cultura. Foi Ferri que, em uma conferencia, affirmou ser impossivel uma guerra, e, com arrebatado ardor oratorio, pediu ao povo brasileiro que deixasse a espada e a espingarda, e tomasse da rabiça do arado, certo de que a prepałação para a guerra era uma inutilidade que nos custava inuteis sacrificios pecuniarios, e sustentou, que a chamada paz armada era a maior calamidade pública dos tempos actuaes. Não! Não foi em vão, não foi sem proveito para a salvação da humanidade que a França, durante mais de 40 annos, se impoz o sacrificio da paz armada, pensando sempre no dia tremendo em que, das margens do Rheno, viriam as hostes inimigas de toda a cultura latina, contrárias ao que, durante seculos, constituimos em prol dos fracos, desejosas de destruirem monumentos, edificios industriaes, tudo o que, com o suor de dezenas de gerações, havia feito aquelle povo que pode ser considerado o pioneiro da civilização, o paladino da liberdade individual, o defensor dos direitos do homem, o francês cheio de generosidade e de espirito cavalheiroso .

Não perderam a cor, nos campos de batalha, nossos avós ao ouvirem o som do clarim bellicoso, não empallidecerão os brasileiros que me ouvem este pregão de guerra. Filhos dos bandeirantes, daquelles que eram insensiveis ao ardor do sol canicular, e ao frio humido das noites dormidas sem tecto e sem leito, dos que não temiam as feras e o gentio, dos que se embrenharam pela floresta virgem nessa vegetação opulenta da região tropical, trabalhados pela fome, corroidos pelas molestias, atraiçoados pelo gentio feroz, affrontando as tempestades, trans- 
pondo rios caudalosos, arrastados em toscos barcos pela corrente rapida de cursos dagua desconhecidos, inexplorados, homens impavidos ao rugir do trovão e ao estoirar dos raios, sobrios, resignados, bravos, heroicos, rompendo a matta negra, sulcando de trilhos a floresta por onde penetraria. a civilização na virgem America, portadores da palavra de Christo e dos conhecimentos dos povos cultos, vós, filhos desses homens de ferro, segundo a elegante phrase de Ruy Barbosa, de bravos que haviam atravessado o oceano em navios de madeira, vós não perdereis a cor das faces, não empallidecereis ao ouvirme, como não se turbaram os europeus, nem mesmo diante do canhoneio atroador de Verdun. Não pode deixar de ser bravo, leal, resistente, abnegado, o povo brasileiro, salvo si falhar tudo quanto ensina a sciencia sobre a herança das qualidades atavicas. Formada nossa raça pelo bravo gentio, pelo cavalheiroso francês, pelo duro e resistente hollandês e pelo leal português, não pode deixar de ter essas peregrinas qualidades de seus antepassados. A coragem do indio brasileiro, não a negou nem mesmo o Visconde do Porto Seguro, tão parcial contra o nosso selvicola. A bravura generosa do francês, só poderá ser contestada pela mais crassa ignorancia da Historia daquelle povo, todo dedicação, todo nobreza. Os versos de Rostand em seu Cyrano e no Aiglon, são o longinquo reflexo da heroicidade da mais nobre nação da Terra. Dos hollandeses herdámos, e vê-se pela resistencia da Bahia ao tempo do $1 .^{\circ}$ imperio, a coragem fria, a calma, a resignação, a firmeza, quando ha a consciencia do nosso direito, qualidades tão vigorosamente celebradas pelo eminente escriptor português Ramalho Ortigão, em seu estudo sobre a Hollanda. Da patria de Pedro Alvares Cabral, temos a gran fidelidade portuguêsa, cantada nos Lusiadas. De Portugal tambem herdámos o espirito aventureiro e a coragem indomita que levava os lusitanos a 
affrontarem todos os perigos do tumido e indomito oceano, aculeados comtudo sempre pela nostalgia dos patrios lares:

\footnotetext{
$O$ viço de meus annos se ha murchado Nas fadigas no ardor sevo de Marte;

Extranhas praias ignoradas gentes.

Barbaros cultos vi, gemi na angustia;

Penei ao desamparo, em soledade,

Vaguei sosinho á mingua e sem conforto

Pelos palmares onde ruge o tigre...

Longe, por esse azul dos vastos mares,

$\mathrm{Na}$ soidão melancolica das aguas

Ouvi cantar a lamentosa Alcyone

$\mathrm{E}$ com ella gemeu minha saudade.

Alta noite, escutei o carpir funebre

Do nauta que suspira por um tumulo

$\mathrm{Na}$ terra de seus paes...

Os ventos pelas gaveas sibilaram;

Duras rajadas de escarceu tremendo

As descosidas pranchas semeavam

Pelas cavadas ondas... Feia morte

Nos acenou co'as roxas agonias

Maldictas da esperança...
}

Foram esses os nossos avós. E nós não deixámos que se perdessem essas nobres qualidades com que um punhado de homens conquistou um mundo, arrancando de Camões os memoraveis versos:

E julgareis qual é mais excellente,

$\mathrm{Si}$ ser do mundo rei, si de tal gente.

Não degenerámos do valor antigo dos lusitanos, e continúa a estuar em nossas veias o sangue que ferveu no Oriente nas de D. João de Castro e de Vasco da Gama. Ahi está a Campanha do Paraguay. E' a ponte de Itororó, que nada fica a dever ao feito de Arcole, da epopéa de Napoleão. E' a batalha de Curupaity, é a de Humaitá, que esperam um Camões, um Garrett, para perpetual-as nas paginas da Historia, jornadas de gloria, luctas homericas, que devem ser postas ao lado de Trafalgar e de 
Aboukir: E' a Retirada da Laguna, tudo quanto ha de mais tragico, diante da qual nada é a dos Dez Mil, immortalizada por Xenofonte: essa lucta tão brilhante quão tragica, foi memorada por Taunay, em paginas palpitantes, e que figurarão ao lado das do grego nas escolas de nossos posteros. 'E' toda ésta guerra terrivel, em que os brasileiros se deixavam ficar dias e dias nos pantanos do sul, faltos de alimentos, sob a metralha inimiga, animados só pelo enthusiasmo e pelo amor da patria, da patria symbolizada pelo nosso pavilhão.

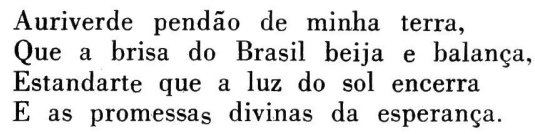

Ainda na revolta, em 1893, na triste lucta civil, testemunho de nossa virilidade, vemos o movimento generoso, a abnegação do povo brasileiro na defesa da causa que abraçára. Apagadas hoje quasi inteiramente as divisões que cavára no povo brasileiro o odio revolucionario, podemos dizer que heroes houve, quer da parte dos revoltosos, quer da dos que se diziam defensores da legalidade. Nada ficámos a dever, em 1893, ao povo francês, mostrámos que conservámos delle as bellas qualidades que se chamam amor á causa pública e coragem. Sim! Custodio de Mello e Floriano Peixoto, passarão á historia aureolados pela mesma fórma por que o foram os antigos heroes, cuja cabeça era cingida pela corôa dos triumphadores, ainda que nas luctas civis não haja vencedores, nem vencidos. Vós, meus concidadãos, vós que me ouvis, tende presente o que devemos á memoria de nossos avós, á defesa de nossa prole e á causa da humanidade. Não consintaes que um povo barbaro domine a Europa, e extenda suas garras sobre a America, que vós defendestes sempre de toda a invasão estrangeira, e onde o extranho só entra como hospede, como amigo para compartir 
comnosco, as doçuras da paz e as luctas para o.dominio sobre a natureza, para melhorar nossa existencia e a dos nossos. Vós sois do mesmo sangue de Caxias e de Osorio, descendeis de Mathias de Albuquerque, de Henrique Dias e de Camarão. Foram nossos avós que condemnaram Calabar, sois vós que poreis termo á espionagem alleman. $\mathrm{O}$ grande patriota padre Vieira levantou sua voz eloquentissima contra os pernambucanos que não lhe pareciam assás energicos contra os hollandezes. Que diria o grande artista da palavra si, hoje, resuscitado, visse nossa patria ameaçada das garras dos allemães? Treme, na sepultura, certamente seu corpo mirrado, si sente ainda alguma coisa dessa vida. O allemão tudo cultivou menos a Moral. E' espião, tem por norma de vida a falsia, rasga os tratados, restabeleceu a fé punica, que causou horror aos romanos, e deverá pois a Allemanha ter a sorte que teve Carthago. Segundo Bossuet, emquanto o povo romano, comquanto pagão, trilhou o caminho da virtude, Deus o favoreceu, e o guiou sempre, dando-lhe continuas victorias. Foi Deus quem guiou o braço forte de Scipião Africano, para destruir Carthago, onde a Moral era egual á do Kaiser. Não sei si tem razão Bossuet. Não sei si era o romano querido de Deus, si seu flagello. E' Elle que ha de permittir que tenha a sorte de Carthago a terra onde se rompem os tratados, e onde a fé punica é objecto de cuidadosa cultura. Refere uma lenda oriental que uma fada offereceu a um homem enorme somma diaria, com a condição de que a gastaria toda no mesmo dia em que a recebesse. Facil foi nos primeiros dias cumprir a cláusula. Mais tarde, teve necessidade de torturar a imaginação, para achar emprego á colossal quantia. Afinal já se haviam esgottado todos os meios de gasto. O proprio jogo, o mais voraz dos consumidores de fortunas, se lhe tornára monotono. Um supplicio ter de dar emprego a todo aquelle dinheiro! Um dia, lembrou-se 
de fazer caridade... e... em beneficiar os necessitados, em vestir e alimentar pobres, em curar enfermos, despendeu facilmente tudo quanto lhe dava a fada. Eis ahi, disse então sua protectora, como facilmente, e com a consciencia tranquilla, empregamos o que nos deu o Todo Poderoso. Dessa lenda lembrei-me, ao ler as primeiras scenas do Fausto de Gœthe. O médico, que recebêra da Providencia divina o mais poderoso dos talentos, gastára a vida em abstrusas sciencias, e acabava desanimado, vendendo a alma a Mephistopheles, e entregando-se á Magia, sem nunca ter se lembrado de applicar sua intelligencia a melhorar a condição dos desgraçados, sem nunca ter pensado em Moral. Fausto synthetiza os defeitos e as qualidades do allemão. Em applicação de sua intelligencia, tudo investiga: Chimica, em que rivaliza com as summidades mundiaes; musica, onde tem as doçuras do mavioso Mozart e as loucuras de Wagner e de Schubert; pintura; altos estudos philosophicos; para chegar, porém, em Moral, ao scepticismo de Schopenhauer ou ao nihilismo de Nietsche, ou á negação por completo de toda noção de Moral. Lá, além do Rheno, tudo progrediu, só a Moral ficou estacionaria, ou antes foi planta que se estiolou. $\mathrm{Ah}$ ! Si, em vez dos gazes asphyxiantes, si em vez dos submarinos assassinos, em vez das doutrinas juridicas que dão a omnipotencia ao Estado, ou antes ao Kaiser, em uma especie de nova idolatria nefanda, houvesse a Allemanha curado de desenvolver as normas de uma san Moral, não teriam tantas viuvas, tantos orphãos derramado um diluvio de lagrimas, acompanhadas de pragas contra o monstro, terrivel Moloch, que exige continuamente o sacrificio de vidas preciosas, fera que nunca se sacia de victimas humanas!... Mas não! Farto de sciencia, foi o dr. Fausto corromper a misera Margarida. Farto de cultura, foi o povo allemão devastar a infeliz e gloriosa Belgica! E' necessario que tenhamos diante de 
nossos olhos que não abandonará Deus aquelles que, confiados em Sua bondade infinita, em Sua Justiça indefectivel, marcharão contra os barbaros assassinos de Miss Cavell: o ceu ha de se abrir, e os raios choverão sobre o exercito do Kaiser, no dia em que os alliados fraquearem, e quando as hostes inimigas da civilização e do Christianismo resistirem ao braço das phalanges que marcham unidas aos franceses.

Comparemos a Allemanha á Inglaterra, comparemos o dr. Fausto aos sabios inglêses, vejamos o abysmo que se abre entre a nação materialista dalem Rheno, e a que vive humanamente á margem do Tamisa. Em uma polemica que Spencer teve com Davies sobre o motivo moral, ou relativa á idéa do dever, coisas de que não poderia se occupar um sabio allemão, pois, em sua patria, o dever é obedecer ao imperador, e as normas moraes são as que o Kaiser prescrever, ou, o que é o mesmo, assassinar, saquear e destruir, disse Spencer que os livres pensadores inglêses, os agnosticistas, tinham, em certa emergencia, sido tão caridosos quanto os christãos. Retorquiu-lhe Davies que, segundo a letra do Evangelho, tambem o samaritano, com seu procedimento, tinha feito vergonha ao sacerdote e ao levita. Ora não nos interêssa, neste momento saber si a caridade é praticada mesmo por aquelles a quem Deus negou a graça, mas só queremos deixar bem firme que, na Inglaterra, sabios christãos e agnosticistas se occupam com essas coisas, e tem na maior estima as pessoas que respeitam o dever, que procedem levadas por motivo moral, e isto ficou bem adquirido pelo accordo entre os dois polemistas.

$\mathrm{Si}$ assim pensam os grandes mestres inglêses, o escol dos intellectuaes daquella terra denominada pinturescamente por Macleod um dos olhos do mundo, não é menos certo que assim pensa o Governo da patria de Gladstone. 
E, grato nos é dizer, ao lado da Inglaterra, poderá figurar, no convivio das nações, a nossa estremecida patria. Em toda sua vida entre as nações cultas, nunca um sô deslise se revelou nos actos do Brasil. Passadas as luctas do $1 .^{\circ}$ imperio, todo entregue ao trabalho da organização, já a regencia foi sempre manifestamente liberal nas relações com os vizinhos mais fracos. Essa fórma de proceder foi quiçá levada a extremo no $2 .^{\circ}$ imperio, e pode-se dizer de nossa patria que foi ella para a America, o que foi a Inglaterra para a humanidade. Ainda mesmo quanto á abolição da escravidão, sabemos que não tivemos susceptibilidades com o Governo inglês, acceitámos tudo quanto, por sentimento de humanidade, quiz a Inglaterra fazer para cohibir o trafico, a mais vergonhosa das affrontas á dignidade humana, das que são mencionadas pela Historia dos povos coloniaes, e as poucas vozes que se levantaram, no Brasil, contra a acção dos cruzeiros da Inglaterra, foram abafadas pelo côro dos brasileiros que tinham presente que todos os homens somos irmãos. Ainda na guerra chamada de secessão, vemos, segundo noticiaram os jornaes, ha pouco, o Imperador do Brasil, desassombradamente favoravel ao Norte, ou á liberdade, e, facto digno de especial menção, suas palavras foram quasi textualmente reproduzidas pelo presidente Wilson, quando, ha mezes, verberava, o procedimento da Allemanha, tolhendo a navegação, e assassinando os pacificos viajantes. Foi o $2 .^{\circ}$ imperio que voou em defesa da Argentina, e, em Monte Caseros, Pharsalia em que triumphou a liberdade, conseguiu, unido a Urquiza, livrar a republica vizinha do despotismo de Rosas. Fomos nós sempre os defensores dos povos fracos que a Providencia collocou a nosso lado neste abençoado continente. Não menos liberal foi o Brasil republica, e Rio Branco e Ruy Barbosa são typos que passarão á posteridade como testemunho das idéas sempre defendidas pelo nosso paiz nas 
relações internacionaes. A aguia de Haya, o anjo da paz, o espirito tutelar das nações fracas, de todos os fracos, o genio que hoje culmina no firmamento da humanidade culta, Sol que brilha neste momento de tempestade contra todas as leis naturaes, aquelle que, por si só, bastaria para tornar nossa patria conhecida onde quer que haja senti mentos christãos, caridade, cultura, fraternidade, altruismo, Ruy Barbosa foi a voz que, na Argentina, definiu, em paginas marmoreas, em tom alevantado, qual o das mais bellas epopéas, o dever dos neutros ante a crueldade dos barbaros que tentam destruir quanto vinte seculos de cultura christan edificou sobre a terra; e Ruy Barbosa é brasileiro, e reflecte o modo de pensar de nossa patria; Ruy Barbosa, digamos, é o Brasil, este Brasil ardente, que, protegido pela bondade divina, poude offerecer ao. mundo um homem dotado da intelligencia de Cicero e de Demosthenes, para dizer na linguagem lapidar dos mestres da palavra, o que pensa o povo, o povo que vive entre os Andes que topetam com os ceus e parecem receber, em seu cimo nublado, a inspiração divina, e o Atlantico, o vasto e tumido mar por onde vamos á culta e velha Europa. Na antiga Judea, quando Deus, com particular caridade, dirigia os passos do povo eleito, um dia, apresentava-se subito no palacio real um propheta, um emissario da Providencia zelosa dos destinos da nação que daria ao mundo o Salvador. Dizia ao rei qual seu dever, obrigava-o a declarar guerra ou a fazer paz, transmittia, em summa, aos homens a vontade do Deus de Israel. Foi assim na America: quando trepidavamos nós americanos diante do atrevimento da Allemanha, quando, hesitantes, não sabiamos si deveriamos arrostar a audacia dos barbaros assassinos dos tripulantes do Lusitania, ou ceder diante de sua força e de sua audacia, ouvimos a voz inspirada do anjo da paz que se erguila no coração da Argentina, e que reboava por todo o mundo culto. Chegou á 
Europa o éco da voz do propheta que traçava com firmeza a linha que deveriam seguir os paladinos da civilização, e a humanidade inteira uniu-se á França e á Inglaterra em defesa do Direito e da Justiça. Tem sido ésta a missão de nossa patria no convivio com as demais nações. Foi ella sempre a pregoeira dos mais alevantados ideaes, e não hesitou em sellar com o seu sangue, no campo de batalha, a liberdade da nação irman curvada sob a mão ferrea do despota que, durante 25 annos, a tyrannizou. A nós brasileiros cumpre manter as tradições da mãe patria, honrar o nome de nossos avós, e sustentar, no campo de honra, as idéas que Ruy Barbosa defendeu na tribuna. Laboriosos na paz, generosos nas relações internacionaes, fortes na guerra, poderemos, si mantivermos, sem um deslise, a rota que temos seguido, ser considerados dignos de nos sentarmos ao lado da Inglaterra nos Congressos internacionaes. Um jornal allemão caricaturou o Brasil (e como são desengraçados os allemães!) representando-o na figura de um preto tropego, ancioso por dar o braço ao distincto cavalheiro Tio Sam. Pois bem! Lembre-se a Allemanha de que Cesar, quando atacava a mocidade garrida de Roma, ordenava a seus veteranos, tostados pelo sol de cem batalhas, que ferissem o elegante inimigo nas delicadas faces, certo de que os efeminados mais amam a tez seductora do que os gilvazes. Saiba a Allemanha que o homem das faces crestadas pelo sol dos tropicos, o pernambucano, o bahiano, o brasileiro nortista em geral, nunca tremeu no campo de batalha, e figurou com denodo nas campinas do sul, ao lado da brava cavallaria riograndense, objecto da admiração e do respeito do mais valente caudilho do seculo XIX, que foi Garibaldi, aquelle que luctou, em 1870, ao lado da França contra a Allemanha, aquelle cujos companheiros, quando aprisionados, eram pela Allemanha arcabusados, sob pretexto de que não formavam 
tropas regulares. "Si lá no assento ethereo... memoria desta vida se consente", hão de os companheiros de Garibaldi, assassinados pelos allemães em 1870, sentir a affronta ao povo que alegremente cantava, sob o commando do filho de Capri, do valente cabo de guerra que se achava onde quer que houvesse uma idéa a defender:

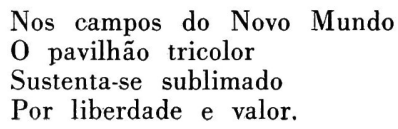

Não foi em vão que o clarim de Caxias e de Osorio chamou a ataque o cavalleiro do Rio Grande, não fugiu o homem no Norte, quando a trombeta soou carga. Foi o bravo caricaturado pelo pasquim allemão que esteve no Passo da Patria, em Uruguayana, em Campo Grande, em Humaitá, em Curupaity, em Avahy, em Itororó, em Riachuelo, em Tuyuti, em Villeta, em Curusú, em Perebebuhy, em Lombas Valentinas, foi elle que correspondeu á bravura de Amazonas, o Farragut, o Nelson brasileiro, foi elle que teve o corpo dilacerado pela metralha, a roupa queimada pelo fogo das batalhas, foi elle que resistiu á mais dura natureza na Laguna, que soffreu das molestias mais terriveis, que, nos acampamentos, teve cholera-morbus, que padeceu fome e sêde, que, trazendo no peito feridas recebidas no campo da honra, póde dizer que nunca abandonou o pavilhão auriverde, até que houvesse sellado, com seu generoso sangue, o triumpho completo da causa da civilização e da humanidade no Aquidaban. Não arrefeceu em nossas veias o sangue dos bravos, que, nos campos do sul, escreveram, com a sua espada, a epopéa que se chamou Guerra do Paraguay, e que, algum dia, será para os posteros objecto de admiração, como o será a lucta que acceitou, no momento actual da vida da humanidade, a civilização contra as atrocidades dos allemães, não recuando diante da mais horrorosa carnificina de que ha 
noticia na Historia do genero humano! Ao rufar dos tambores, ninguem que tenha sangue de brasileiro recusará a defesa dos patrios lares e da causa da civilização. Não se trata porém, só da defesa dos principios christãos postos em perigo pelos ferozes idolatras das margens do Rheno. Vae, na lucta, mesmo nosso interêsse. E' a nossa integridade que se acha ameaçada. O perigo allemão é uma realidade, e não um lugar commum, com que os jornaes brasileiros fornecem pasto aos nervos dos seus leitores. Demais se tem provado que nossa extrema bondade foi explorada pelos nossos desleaes inimigos. Demais foram adduzidas provas incontestaveis de que a vibora a que deramos agasalho em nosso seio, já começára a picar. Já todos sabemos que elles tentaram pôr por obra o que disse, em uma canção patriotica, Arndt: "Póde o allemão chamar sua, e deve ser sua, a terra em que soar a lingua allemã". Não é aquem, nem além do Rheno que está a patria do allemão, disse o poeta que segundo um profundo sociologo, soube traduzir, em fórniula precisa, o pensamento do allemão, não é sô a Baviera, nem só a Prussia a patria do allemão, mas toda terra em que soar a lingua allemã, e onde quer que a Deus entoem nella os allemães hymnos, e assim deve ser, a esta o bravo allemão póde chamar sua. Naturalmente, falla Arndt dos hymnos ao feroz deus da guerra, nas cerimonias religiosas em que bebiam os sacerdotes pelos craneos dos inimigos...

A vós, campineiros, a quem eu dirigi minhas primeiras palavras nesta santa cruzada, a vós nascidos na cidade onde vi a luz primeira, e na qual creio que nasceu Feijó, cabe o dever de dar exemplo que déstes em 1893, quando daqui partiram os batalhões que seguiram para Itararé, a conter a marcha triumphante de Gumercindo Saraiva. Levavam em seu seio, o escol da sociedade campineira: deixaram familia, interesses, conforto, e, em 
defesa do idéal que periclitava, ameaçado pelas hostes do sul, marcharam para Itararé e para a Lapa.

A Campinas, mais do que a qualquer outra cidade, deve o Brasil ter sido detido o exercito invasor, quando marchava para as Thermopylas de São Paulo.

A vós, resolvidos á reproducção da resistencia dos 300 espartanos, que, sob o commando de Leonidas, morreram para obedecer ás leis de Esparta, e para defender sua patria, a vós corre o dever de, antes de todos, offerecer os serviços á patria e á humanidade. Não se tracta, neste momento, de tomar armas para marchar para as trincheiras da frente dos alliados. Não é preciso seguir já, a tomar lugar na vanguarda do glorioso exercito que se bate nas fronteiras dos povos civilizados. Cumpre entretanto estarmos preparados para qualquer tentativa dos audazes inimigos do genero humano.

E' necessario auxiliar nosso governo na lucta contra a espionagem, tão desenvolvida que, com razão, foi dado á patria de Guilherme o cognome da Espiolandia; é indispensavel adextrarmo-nos no exercicio das armas, affazermo-nos á vida do soldado, intensificarmos a campanha economica, tão acertadamente iniciada pela Inglaterra com a blak list, que tanta opposição tem achado da parte do egoismo de certos interessados, mas de interessados que não comprehendem seus verdadeiros interesses.

Em outras conferencias ulteriores, desenvolverei o que penso sobre o modo por que desde já devemos reagir contra o dominio economico dos allemães. Antes, porém, direi da origem da guerra e da responsabilidade de Guilherme, de seus crimes, de sua preoccupação de dominar o mundo e do dever em que nos achamos de auxiliar os alliados, particularmente após a traição da Russia. Chama por nós a patria brasileira ultrajada em nossos navios torpedeados, chama por nós a humanidade vilipendiada 
na invasão da Belgica e no assassinato da tripulação do Lusitania. Quando mais tarde, seculos depois de finda a lucta entre a civilização e a barbaria, o historiador imparcial julgar o procedimento de nosso Brasil, ha de collocar o nome de nossa patria ao lado do daquelle povo que auxiliou seus irmãos na Grecia a deter a marcha do exercito de Xerxes.

Eis fixado o dever de todo bom patriota, de todo cidadão que comprehende a necessidade moral de defender a terra em que nasceu, o lar, a familia, as instituições creadas pelos avós, e transmittidas tradicionalmente, emfim isto que se venera, que muito mais se ama que a propria vida, e que se chama a patria... Mas é de repetir qual o dever dos cidadãos a quem foi confiado zelar os interesses sociaes, vigiar para que não soffra detrimento a Republica, na phrase dos romanos, dizer ao povo o que lhe cumpre fazer, e, nesta classe, acham-se os delegados do povo e os intellectuaes, aquelles que uma escola moderna diz formarem a classe contemplativa dos Estados cultos. Um apologo fará claro qual o dever dos que se dedicam aos estudos sociaes, sabedores da Historia, Sciencia da Administração, Politica e Sociologia. Conta-se que, fatigado pelo trabalho, deixou-se adormecer um homem fóra de casa. Ao despertar notou que fôra victima de um furto. Queixou-se á autoridade, e ésta respondeulhe que tinha elle sido imprudente, deixando-se dominar pelo somno sem nenhuma cautela, e que merecida era a pena que lhe havia sido infligida pelo ladrão.

Senhor, revidou o queixosø, eu dormia tranquillo, suppondo que vós zelarieis meus cabedaes e minha pessôa. Nós tambem, autoridades e intellectuaes, devemos estar vigilantes, emquanto vós labutaes, e, a espaço, repousaes, seguros de que nós estamos alerta, para que não soffra a patria o assalto dos inimigos. Cumpre que confieis em nós, e que acrediteis que não são imaginarios os 
perigos de que vos advertimos. E' tempo de preparar a guerra, para estarmos seguros da paz. E' tempo de vos lembrardes de que, luctando sómente com a natureza aspera da America, não tendes cumprido todo vosso dever: resta ainda luctar contra aquelles que pretendem tomar, de vós e de vossos filhos, aquillo que conquistastes com tanto soffrimento, o pão banhado de vosso suor, a terra regada com o vosso sangue, o lar onde tem havido risos e lagrimas, e que todos amamos, a casa onde tivemos alegrias e dores. Eis, meus concidadãos, meus conterraneos, 0 meu pregão, eis as palavras que todos que verdadeiramente estimam a patria devem vos dizer, e a advertencia que vos faço não será perdida, ainda mesmo que a imprensa, mais poderosa hoje de que a Fama da antiguidade pagan, annunciar amanhan que o Kaiser se rendeu á discrição do vencedor, que a Allemanha pede a paz sem condições, porque o caçador prudente só com a maior cautela se approxima da hyena que parece morta.

Eis minhas ultimas pálavras aos campineiros, as primeiras nesta sancta cruzada. Praza a Deus ecoem ellas na terra onde nasceu Carlos Gomes, que tornou celebre na Europa, pelas maviosas melodias do Guarany, o nome brasileiro.

Braz de Sousa Arruda,

Docente da Faculdade. 